\title{
POLÍTICAS PÚBLICAS E PARTICIPAÇÃO SOCIAL: UM DEBATE ENTRE A IDENTIDADE E O DESENVOLVIMENTO TERRITORIAL
}

\author{
Bruno Abdala Vieira Di Coimbra ${ }^{1}$
}

\section{Resumo}

Este artigo, de maneira geral, trata das políticas públicas e da participação social. O interesse particular está em relacionar essas temáticas com o papel da identidade na construção do desenvolvimento territorial rural. A identidade é entendida aqui como um processo, marcado por relações de poder. A afirmação da identidade, nesse sentido, tem papel fundamental na demarcação dos interesses e demandas de populações atendidas por políticas de desenvolvimento. Ao longo do texto, apresentam-se os contextos que marcam a mudança de perspectiva das políticas públicas, que passam a promover a participação social e a territorialização de ações governamentais. Pondera-se, entretanto, a necessidade de que tais políticas garantam que processos decisórios possam, de fato, serem revertidos em ações concretas.

Palavras-chave: Identidade. Políticas Públicas. Participação. Desenvolvimento Territorial.

\section{PUBLIC POLICY AND SOCIAL PARTICIPATION: A DEBATE BETWEEN IDENTITY AND TERRITORIAL DEVELOPMENT}

\begin{abstract}
This article, in a general way, is about public policy and social participation, with the focus in bringing closer together this debate to the role of identity in the construction of rural territories development. Identity here is understood as a process, marked by power relationships. Identity affirmation, in this context, has a key role in the determination of interests and demands of populations covered by development policies. It is shown, throughout the paper, contexts that mark a change of perspective in the public policies, wich started to promote social participation and territorialization of government actions. The article also considers that this policy needs to guarantee that decision processes are indeed turned into concrete actions.
\end{abstract}

Key words: Identity. Public policy. Participation. Territorial Development.

\section{POLÍTICAS PÚBLICAS Y PARTICIPACIÓN SOCIAL: UN DEBATE ENTRE LA IDENTIDAD Y EL DESARROLLO TERRITORIAL}

\section{Resumen}

\footnotetext{
${ }^{1}$ Doutorando pelo Programa de Pós-Graduação em Geografia da Universidade Federal de Goiás. Vinculado ao Laboratório de Estudos e Pesquisas das Dinâmicas Territoriais (Laboter/IESA/UFG).

E-mail: abdalabr@gmail.com
} 
Este artículo, de manera general, trata sobre política pública y participación social, con el objetivo de acercar este debate al papel de la identidad en la construcción del desarrollo de los territorios rurales. La identidad aquí se entiende como un proceso, marcado por relaciones de poder. La afirmación de identidad, en este contexto, tiene un papel clave en la determinación de los intereses y demandas de las poblaciones cubiertas por las políticas de desarrollo. A lo largo del documento, se muestran los contextos que marcan un cambio de perspectiva en las políticas públicas, que comenzaron a promover la participación social y la territorialización de las acciones gubernamentales. El artículo también considera que esta política debe garantizar que los procesos de decisión se conviertan en acciones concretas.

Palabras clave: Identidad. Política Pública. Participación. Desarrollo Territorial.

\section{INTRODUÇÃO}

Observa-se, nas últimas décadas, especial entusiasmo em relação a discursos e práticas que buscam valorizar o desenvolvimento a partir de sua dimensão espacial. Assim, assiste-se a uma tendência no desenho de políticas públicas que acionam o lugar, o território, os atores e agentes ${ }^{2}$ locais, considerando-se que as disparidades sociais, econômicas, culturais e ambientais possam ser solucionadas, quando necessárias, a partir de um tratamento territorialmente diferenciado. Além disso, o envolvimento de atores sociais em seus contextos territoriais específicos, para essa compreensão, possibilitaria a promoção de processos de governança, ampliando-se a capacidade de coesão territorial e aproximando o desenvolvimento dos interesses sociais.

No espaço rural, desde a década de 1990, uma série de ações, projetos, programas e políticas passaram a experimentar semelhantes concepções de desenvolvimento. No Brasil, destacam-se o Programa Nacional de Desenvolvimento Sustentável de Territórios Rurais PRONAT e o Programa Territórios da Cidadania - PTC. Lançados, respectivamente, nos anos de 2003 e 2008, o PRONAT e o PTC são programas que articulariam políticas e atores em torno de uma estratégia integrada de desenvolvimento territorial sustentável. Ambos têm como objetivos melhorar infraestruturas e serviços em recortes territoriais compreendidos como de baixo dinamismo econômico, buscando "acelerar a superação da pobreza e das desigualdades sociais no meio rural, inclusive as de gênero, raça e etnia [...]” (BRASIL, 2008, n.p).

\footnotetext{
${ }^{2}$ Segundo Ferreira (2013, p. 55) “aos atores relaciona-se o agir como fonte de um processo; a eles são atribuídas capacidades e intenções. Ao falarmos em atores, estamos nos referindo a jogos de poder, relações de força que põem em disputa conhecimentos e estratégias que constroem encadeamentos sócias e políticos. Os agentes, embora também se realizem no âmbito do agir, são passivos no que tange à definição de intencionalidades".
} 
Compreende-se que os programas citados, embora encontrem obstáculos na sua execução, são importantes para a reorganização de forças presentes em dada escala nacional, aproximando atores sociais do protagonismo de pensar uma agenda de desenvolvimento para seus contextos territoriais. Além disso, ambos os programas estiveram desenhados para fortalecer a estratégia de territorialização de outro conjunto de políticas: Programa Bolsa Família, Programa Nacional de Acesso ao Ensino Técnico e Emprego - Pronatec, Programa Nacional de Fortalecimento da Agricultura Familiar - Pronaf, Programa de Aquisição de Alimentos - PAA e Programa Nacional de Alimentação Escolar - PNAE.

Por esse viés, atenta-se a três observações vinculadas a esse quadro. A primeira está relacionada à qualidade dos processos participativos, referentes aos novos espaços instituídos - colegiados territoriais - que, supostamente, são capazes de afetar o movimento de formulação e de implementação de políticas públicas em recortes territoriais particulares. A segunda, reporta-se aos efeitos da territorialização do outro conjunto de políticas, citadas acima, sobretudo aquelas vinculadas à compra de alimentos por mercados institucionais - PAA e PNAE. Já a terceira, foco deste texto, debruça-se sobre o papel da identidade na construção das estratégias do desenvolvimento territorial. De maneira que esta última concentra atenção dupla: tanto no público-alvo das ações governamentais supracitadas, quanto nos próprios desenhos institucionais de tais políticas.

Destarte, o propósito é discutir a importância da identidade em políticas públicas que têm como horizonte um desenvolvimento assentado não apenas no crescimento econômico, mas também social, cultural e ambiental.

$\mathrm{O}$ artigo se estrutura em três partes, além da introdução e das conclusões. Na primeira, busca-se abordar a identidade com a finalidade de realçar a sua importância na construção de um desenvolvimento emancipatório - no sentido atribuído por Sen (2002). Em um segundo momento, discorre-se sobre as mudanças nos debates envolvendo políticas públicas, que passam a valorizar a participação e a governança. Por último, discute-se a participação social nas políticas de desenvolvimento rural no Brasil, manifestando seu contexto.

\section{A IDENTIDADE COMO ELEMENTO DO DESENVOLVIMENTO TERRITORIAL}

Tuan (1980, p. 15), quando apresenta seu estudo sobre as percepções, afirma que a partir da linguagem "os seres humanos construíram mundos mentais para se relacionarem entre si e com a realidade externa". O autor, entretanto, parte da ideia de que cada pessoa ou grupo social 
tem uma maneira distinta de perceber e avaliar tais relações. Ou seja, não há uma construção única pertinente a todo o conjunto social. Essa diversidade de "mundos", ou multiplicidade de culturas, é resultado, dentre tantos outros elementos, de tempos e espaços - ou, nas palavras do autor, de "épocas" e "lugares" distintos.

Embora a sentença apresentada não contemple o volume de questões e debates levantados por aquele estudo - e há mais elementos que podem ser acionados -, já é possível reconhecer que não há projetos humanos (econômicos, políticos, sociais ou culturais) que possam abarcar a soma da sociedade sem que se despertem conflitos de interesse, ou mesmo confrontos, a partir de posições díspares e até antagônicas do modo de interpretar a realidade. A assimilação de que somos diferentes e compreendemos o mundo, cada qual, de uma maneira mais ou menos particular, provoca a reflexão: o desenvolvimento não deve estar descolado da presença dos mais variados atores aos quais ele é objeto de relevância. E é também a partir do exposto que a preocupação com o papel da identidade nesse processo torna-se evidente.

Importa salientar que, assim como explicita Castells (1999, p. 22), "entende-se por identidade a fonte de significado e experiência de um povo". E quanto aos atores sociais, a identidade se refere ao "processo de construção de significado com base em um atributo cultural, ou ainda um conjunto de atributos culturais inter-relacionados o(s) qual(ais) prevalece $(\mathrm{m})$ sobre outras fontes de significado" (CASTELLS, 1999, p. 22). Encontra-se aqui também a possibilidade de identidades múltiplas que, segundo o autor, é razão de tensões e contradições, seja na auto-representação, seja na ação social - o que novamente fortalece a necessária presença de atores sociais no embate dos fundamentos que afetam amplamente a vida comum.

Do ponto de vista sociológico, afirma aquele autor, não restam dúvidas de que toda identidade é construída. As perguntas relevantes, no entanto, são aquelas que revelam a partir de que, por quem e para que esses processos de construção da identidade existem. A resposta apresentada parte da premissa de que a construção da identidade é fruto de um conjunto de fatores históricos, geográficos, biológicos, mas também referentes às instituições produtivas e reprodutivas, das memórias coletivas e fantasias pessoais. Entram nesse quadro, ainda, os aparatos de poder e os de cunho religioso. Para além, importa frisar que "a construção social da identidade sempre ocorre em um contexto marcado por relações de poder [...]" (CASTELLS, 1999, p. 24). 
A construção e a luta para afirmação da identidade, como afirma Cruz (2007), significa atuar no sentido de evidenciar as especificidades de um grupo e, com isso, marcar projetos e interesses próprios. É nesse sentido que tanto a definição discursiva, quanto a linguística da identidade estão submetidas a vetores de força e, consequentemente, a relações de poder. Para o autor, essa perspectiva assinala a identidade em uma relação entre o "cultural” e o "político", duas dimensões imbricadas. Assim, "por essa íntima relação com o poder que a identidade não pode ser considerada de maneira essencialista, mas estratégica e posicional." (HALL, 2004, apud CRUZ, 2007, p. 19).

Com base nesse ponto, certifica-se a importância desse debate na geografia, pois, como pontua Almeida (2004, p. 109), inspirada em Martins (1997), é no espaço que as estratégias identitárias são aplicadas; "É o espaço que fornece ao sujeito um campo para suas realizações existenciais, físicas e organizacionais. Investir fisicamente um lugar é, ao mesmo tempo, instituir um território [...]”. É nesse sentido que, ainda por meio de Almeida (2004, p. 112), mas já com proposta de Haesbaert (2001), compreende-se que a identidade “depende profundamente dos constructos referentes a determinados recortes geográficos, tenham eles um caráter mais concreto ou mais abstrato. Todo esse universo, pela sua dinâmica histórica e política, nos revela o território", sendo este, "local de [conflito e, por vezes,] confronto das manifestações dos grupos sociais" (ALMEIDA, 2004, p. 112).

É nesse sentido que o território e a diversidade territorial devem ser compreendidos no tratamento das políticas públicas. Não se trata apenas de reconhecer uma diferenciação regional, econômica, social, ou mesmo cultural do ponto de vista do planejamento estatal, mas de elementos intrínsecos à cultura e à maneira como a identidade se manifesta nas disputas por interesses. Pois é no território, como pontua Haesbaert (2009), que as espacialidades das relações de poder se manifestam, sendo que este pode ser concebido a partir das múltiplas relações de poder - desde as mais materiais, referentes às relações econômico-políticas, até as mais simbólicas, pertencentes a uma ordem especialmente cultural.

Pode-se argumentar que os projetos de futuro, que almejam atores territorialmente assentados, são frutos de suas vivências, seus referenciais, desejos e intenções. Por mais que um ator faça parte de uma sociedade com características próximas, há sempre sintomas que os diferem de seus pares e os fazem perseguir um horizonte particular nas expectativas do desenvolvimento. Reconhecer a necessidade da participação social em espaços decisórios é admitir tal diversidade e respeitá-la. 
É certo que a globalização, como salienta Cruz (2007), vem redefinindo as experiências sociais quanto à construção e afirmação das identidades territoriais que, cada vez mais, operam a partir de um jogo de escalas entre múltiplos tempos e espaços. O processo de afirmação da identidade, nesse sentido, tem redefinido a dinâmica cultural e a política atual. Como rememora o autor, fala-se em "poder da identidade, "moda da identidade, "consumo de identidades" etc.: novas configurações marcadas pelo hibridismo - ou seja, nega-se o discurso sobre pureza ou essência cultural na construção de identidades. Assim, verifica-se que o debate sobre a questão identitária remete às problemáticas que envolvem a articulação entre subjetividade e política, repensando categorias como classe, etnia, raça, entre outras, que, por muito tempo, foram "referência para se pensar a ação, a política e, consequentemente, o território" (CRUZ, 2007, p. 14).

Cruz (2007) pergunta se há um fraturamento, ou mesmo um deslocamento, das posições do sujeito moderno. Já Hall (1997) questiona se não é a própria modernidade que está sendo transformada. Embora não se concorde exatamente com Hall, na afirmativa de que o sujeito anterior a essa mudança - tinha uma identidade unificada e estável, acredita-se que, com a aceleração da globalização, esse sujeito está cada vez mais fragmentado e várias identidades passam a compor sua vivência - "algumas vezes contraditórias ou não-resolvidas" (HALL, 1997, p. 13). Nesse sentido, o autor falará que “a identidade se torna uma 'celebração móvel': formada e transformada continuamente em relação às formas pelas quais somos representados ou interpelados nos sistemas culturais que nos rodeiam” (HALL, 1997, p. 13).

Tanto Hall (1997) quanto Cruz (2007) parecem concordar que identificações exclusivamente baseadas em classe não contemplam mais o eixo mobilizador, por meio do qual os atores ou as identidades possam ser representadas. Talvez essa seja uma das questões que, hoje, acentua o sentimento social de não representatividade nos espaços políticos tradicionais. Mais uma vez, há indícios de que novos espaços multiescalares devem ser criados para abrigar as mais distintas disputas por interesses, dando legitimidade aos anseios identitários na promoção do desenvolvimento.

Veremos adiante que, de alguma forma, tais manifestações passaram a ser incorporadas no debate em torno de políticas públicas. No espaço rural, em especial, as estratégias de desenvolvimento passaram a incorporar, ao menos em tese, o discurso da governança territorial: processo de concertação a partir da participação de atores sociais. 


\section{INOVAÇÕES NAS POLÍTICAS PÚBLICAS: PARTICIPAÇÃo E GOVERNANÇA TERRITORIAL}

O PTC e o Pronat são frutos de desdobramentos relativos a transformações na forma de produzir, executar e analisar políticas públicas em muitos países ocidentais. Os programas são resultados de um contexto político de valorização da participação social e da territorialização de políticas públicas, ou seja, de um fortalecimento da suposição de que é "localmente, e não mais a partir das escalas de decisão de escopo nacional, que determinados problemas devem ser identificados e suas soluções elaboradas." (RODRIGUES, 2013, p. 88).

São diversos os olhares que buscam interpretar essas mudanças nas políticas públicas e cada perspectiva tende a salientar determinado aspecto. Um exemplo interessante é apresentado por Fuini (2010), que alcança o centro da questão, tendo em vista a transição do modelo regulatório de acumulação fordista-keynesiano para um modelo de produção e acumulação flexível - ainda em ritmo. $\mathrm{O}$ foco dessa ideia é que essa transição tem contribuído, de alguma maneira, para uma suposta intensificação da especialização produtiva de regiões e localidades inseridas em espaços subnacionais - acirrando formas de mobilização de recursos e concorrência intranacional e internacional.

De acordo com essa leitura, a mobilização de recursos ocorreria por meio de arranjos propícios para articular instituições em projetos de desenvolvimento valorizados a partir de atores, capacidades e conhecimentos específicos. Esse processo sucederia em novas estruturas de governança territorial, ascendendo uma estratégia para impulsionar a competitividade de espaços subnacionais - sendo "a governança" uma forma de organização complexa com certo grau de cooperação. Nesse sentido, Fuini (2010) salienta que os recursos mobilizados podem ser de dois tipos: aqueles de qualidade genérica, transferíveis e comuns a outros contextos territoriais ou aqueles mais específicos, referentes à convergência de experiências históricoculturais decorrentes "de articulações sociais e espaciais inéditas" (FUINI, 2010, p. 20). O resultado desse acordo envolvendo atores e instituições orientaria a governança a um objetivo máximo: o desenvolvimento territorial.

Já Favareto (2009) parte de uma outra perspectiva para explicar as alterações nas políticas públicas. Embora este autor esteja inserido no debate em torno do desenvolvimento territorial, o seu foco é o espaço rural. Para Favareto (2009, p. 53), a territorialização das 
políticas, em conjunto com a valorização da participação social - e que tem como pano de fundo a "emergência daquilo que se convencionou chamar de abordagem territorial do desenvolvimento rural" -, está imbricada a três ordens de fatores.

A primeira delas se refere a uma mudança de perspectiva, ou seja, saindo de uma compreensão do rural como setorial - compreendido quase exclusivamente como espaço da agricultura e da pecuária - para outra mais integrada, reconhecendo outras dinâmicas associadas e importantes no processo de desenho de políticas públicas. Em segundo lugar, a valorização da dimensão espacial como um componente fundamental para medidas alternativas de desenvolvimento, inclusive na adoção de outras escalas para alocação de recursos. O terceiro ponto está na crença de que medidas top down ou "de cima para baixo" deveriam ser equilibradas, ou até mesmo substituídas, por intervenções bottom up ou "de baixo pra cima", e que isso deveria ser um mecanismo para o direcionamento de investimentos públicos (FAVARETO, 2009).

Nesse caso, a mudança no referencial das políticas é explicada pela adesão de outras escalas para o redirecionamento de recursos e pela substituição do enfoque setorial pelo territorial. Segundo o autor, essa transformação possibilitaria uma visão mais estratégica e integrada do desenvolvimento rural. Outro ponto importante é a decorrência da incorporação do princípio de subsidiariedade ${ }^{3}$, o que resultaria em estratégias de governança territorial por meio de intervenções "de baixo pra cima".

Ferrão (2014, p. 55) compreende que o novo olhar sobre a maneira de produzir, executar e analisar políticas públicas é evidenciado em um quadro ainda mais amplo, de "erosão da visão racionalista e positivista moderna de Estado, economia e sociedade por concepções póspositivistas". A erosão da qual fala o autor englobaria a transformação do significado social de conceitos como o de interesse público, planejamento e território, e seria motor para a produção de políticas de ordenamento baseadas em visões "de natureza mais integrada, estratégica e prospectiva" (FERRÃO, 2014, p. 33).

A análise do autor reflete que, por meio dessa nova visão, as políticas passaram a ser ajustadas com base em: i) valorização da pluralidade de atores, interesses e valores, ii) fomento à integração de políticas setoriais, tendo como referência uma base territorial em que pese o iii)

\footnotetext{
3 “A subsidiariedade é um princípio de administração privada ou pública que considera que a decisão deve ser tomada pelo centro de decisão que (1) conheça melhor o problema e a maneira de solucioná-lo e (2) que tenha mais interesse na resolução do problema". (BONNAL; MALUF, 2007, p. 5) 
interesse público, invocado por demandas negociadas em processos de planejamento participativo e de governança territorial. Esta, por sua vez, é explicada pelo autor como parte da passagem de um paradigma de "'governo〉 (estatal, vertical, hierárquico, burocrático) para um outro de 〈governança〉 (coordenação horizontal e vertical entre múltiplos atores-públicos, privados e associativos - envolvidos em projetos comuns)" (FERRÃO, 2012, p. 23).

Percebe-se que as diferentes vertentes ajudam a explicar a transformação na maneira de pensar as políticas públicas. Em todas elas e, em grande parte da literatura sobre o tema, há em comum elementos relacionados à valorização da dimensão espacial - por meio da territorialização das políticas - e da participação social, tendo em vista práticas de governança em escalas decisórias locais.

Pode-se pontuar que as concepções apresentadas falam em atores, capacidades e conhecimentos, em experiências histórico-culturais - também diríamos espaciais -, em decisões tomadas por quem conhece o problema e tem maior interesse em resolvê-lo e ainda em demandas negociadas, pluralidade de atores, interesses e valores. Além disso, todas remetem, de alguma maneira, à reformulação do papel do Estado e à descentralização políticoadministrativa. A esse ponto, Ferrão (2012, p. 23) acrescentaria ainda o debate sobre a democracia participativa e deliberativa e certa "europeização" dos processos de decisão ${ }^{4}$.

No Brasil, contudo, outros fatores ajudaram a justificar tais mudanças, como o fim do regime militar (1964 a 1985), a promulgação da Constituição de 1988, a consolidação do modelo democrático liberal e a abertura econômica. Foram esses movimentos que deram forma à descentralização e a recentralização político-administrativa, à reorganização dos entes federativos, à valorização dos distintos poderes, ao reconhecimento de novos atores sociais e à abertura de canais de diálogo e participação entre Estado e sociedade civil.

Nesse sentido, a Carta de 1988 teve significativa importância e pode ser apontada como um marco de transformação tanto para o Estado quanto para a sociedade civil. A Constituição Cidadã, como por muitos é atribuída, abriu caminho para o avanço da descentralização políticoadministrativa - mesmo que ela própria, em sua formulação, tenha permitido uma sucessiva recentralização do papel da União ao longo dos anos (ARRETCHE, 2012). Entretanto, o texto aprovado foi responsável pelo reconhecimento formal de atores políticos, de alguma autonomia aos entes federativos e de maior participação social nos processos políticos - inclusive em

\footnotetext{
${ }^{4}$ Embora seja um autor Português, e relate especialmente o caso de ordenamento do território europeu, suas considerações contribuem para uma análise do contexto de transformação nas políticas de maneira ampla.
} 
espaços e instâncias que aparentemente não fazem parte dos processos eleitorais tradicionais, como são os casos dos conselhos, fóruns, colegiados etc.

Um marco temporal, argumentam Grisa e Schneider (2015), não consegue sintetizar completamente os processos sociais e suas transições. Contudo, é notório que nas últimas três décadas um conjunto de mudanças ocorreram no país - seja no âmbito político-institucional ou nas dinâmicas sociais. E foi com esse cenário que novas regras e instrumentos de políticas públicas puderam ser criados. Apoiados em novos referenciais - tanto globais quanto setoriais ${ }^{5}$ -, essas regras e instrumentos contribuíram para alterações nas formas de atuação do Estado, influenciando, em algum grau, as condições socioeconômicas das populações - em especial as rurais.

\section{A PARTICIPAÇÃO SOCIAL NAS POLÍTICAS DE DESENVOLVIMENTO RURAL NO BRASIL}

A reflexão sobre a participação social nas políticas de desenvolvimento rural no Brasil requer um retorno breve ao debate sobre a mudança no referencial das políticas públicas. Como visto, essas modificações impulsionaram certa territorialização das ações governamentais e incentivaram o discurso em torno da valorização da participação social por meio de uma visão mais integrada e estratégica do desenvolvimento - nesse quadro, insere-se o debate sobre a “governança territorial”. Muitas são as formas de ler essas transformações e de explicá-las, mas, de modo geral, parecem ser fruto de um movimento mais amplo, é nesse sentido que Ferrão (2012, p. 130) dirá que se trata de alterações estruturais, relacionadas "à crescente perda de vigor [...] do modelo moderno e racionalista de Estado".

Bonnal e Maluf (2009), atentos ao contexto brasileiro, salientam alguns aspectos que tiveram peso nessa conjuntura. Em primeiro lugar, destacam que esse "novo" referencial é coerente com a reforma político-administrativa que vem ocorrendo no país desde a redemocratização, e que esse processo foi marcado pela "instituição e fortalecimento do modelo democrático-liberal" (BONNAL; MALUF, 2009, p. 221). Segundo os autores, e como já salientado, alguns eventos importantes desse período merecem destaque como, por exemplo, a elaboração da Constituição de 1988, a abertura econômica, a reforma das instituições públicas, a reforma fiscal de 1988, a privatização de empresas públicas e o tratamento da crise da dívida.

\footnotetext{
5 Trata-se de uma perspectiva da abordagem cognitiva para a análise de políticas públicas. Ver contribuições de Jobert e Muller (1988); e Fouilleux (2011). 
Outra questão salientada pelos autores é que, a partir de 1990, o país passou a implementar, mesmo de forma incipiente, políticas de ordenamento territorial e de desenvolvimento regional consoantes com a orientação constitucional. Além do mais, esse foi um momento propício para a reorganização dos movimentos sociais agrícolas e rurais, para a emergência da agricultura familiar como categoria sociopolítica e de maior cuidado para com as identidades de populações quilombolas, ribeirinhas e outras minorias - o que, sem dúvida, serviu de suporte para discussões de políticas diferenciadas.

Um ponto relevante sobre a expansão do modelo democrático liberal, do qual falam os autores, é que, alinhado à crise econômica dos anos de 1980, ela pode ser entendida como uma das chaves para o avanço do projeto neoliberal que se intensificou no Brasil a partir da década de 1990. Outra particularidade, que diz respeito a esse quadro histórico, é a confluência entre o projeto neoliberal e o participativo/democratizante, manifestado ao fim da ditadura militar e afirmado pela Constituição. Segundo Dagnino (2004), ambos encontravam, à época, ambiente favorável para serem estabelecidos no país e, mesmo que com horizontes distintos, demandavam uma sociedade atuante politicamente.

Essa conjuntura, como narram Grisa e Schneider (2015), atuou no fortalecimento dos movimentos sociais e dos sindicatos da agricultura familiar, que passaram a adotar também uma postura de parceria com os governos quanto à execução de políticas públicas. Porém, isso não quer dizer que abandonaram lutas históricas e outras mobilizações, reivindicações e manifestações de seus interesses. O desenrolar desse processo, de acordo com os autores, fez com que, a partir da segunda metade da década de 1990, um número crescente de políticas e programas passassem a envolver as organizações da sociedade civil em seus processos de formulação e operacionalização.

São esses aspectos, somados à incorporação da noção de sustentabilidade, como coloca Schneider (2010), que contextualizam o surgimento das discussões acerca do desenvolvimento rural no Brasil nessa década. Para o autor, quatro fatores fundamentais guiam a emergência desse debate: 1) as questões relacionadas à agricultura familiar; 2) a maior participação do Estado no meio rural, influindo em ações e na legitimação das reivindicações dos movimentos sociais; 3) certas mudanças de compreensão política e ideológica, que polarizavam as formas familiar e patronal de produção; e 4) a valorização das ideias acerca da sustentabilidade ambiental. 
Além disso, como bem pontua Montenegro Gómez (2006), é preciso admitir a influência do Banco Mundial nessa conjuntura de reformulação das políticas agrárias em uma política de desenvolvimento rural. Em documento lançado em 1994, intitulado Brazil: the management of agriculture, rural development and natural resources ${ }^{6}$, o órgão recomenda a adoção de um novo enfoque para o rural brasileiro, reduzindo o papel do Estado e criando maiores condições para atuação do mercado. O caminho indicado seria o fortalecimento da agricultura familiar, integrando pequenos e médios agricultores ao mercado e destinando a eles papel-chave para o desenvolvimento rural.

Aparentemente, essa não era uma postura isolada do Banco Mundial, e se olharmos para os anos de 1990 e início dos 2000, perceberemos que uma diversidade de instituições multilaterais pautou discussões acerca de políticas públicas; sobretudo aquelas direcionadas aos espaços rurais dos países entendidos como em desenvolvimento. Certamente, nem todos os relatórios apresentam as mesmas propostas, mas, em geral, recomendam o reconhecimento de novas dinâmicas espaciais e a necessidade de novos instrumentos governamentais. Para citar alguns estudos: os da OCDE em 1993 e 1995, os da Cepal em 2003, FAO em 2004 (FAVARETO, 2009; HESPANHOL, 2010) e como já dito, aquele produzido pelo Banco Mundial em 1994, mas também em 1995, 1997, 2001 e 2005 (SOUZA, 2014).

Um dos resultados mais significativos dessa mudança de concepção, com o foco na ideia de desenvolvimento rural, se dá no Governo de Fernando Henrique Cardoso, com a criação, em 1995, do Programa Nacional de Fortalecimento da Agricultura Familiar. Essa é uma das políticas mais importantes voltadas para o setor da agricultura familiar e marca o reconhecimento do Estado no que se refere a essa categoria (GRISA; WESZ JUNIOR; BUCHWEITZ, 2014). Além disso, o Programa propunha o combate às "desigualdades que marcaram tradicionalmente as políticas estatais voltadas para estimular a mudança da base técnica da agricultura do país" (AQUINO; SCHNEIDER, 2015, p. 54).

Com o Pronaf, nesse sentido, o Governo brasileiro demonstrou algum alinhamento com as sugestões do Banco Mundial bem com os movimentos sociais que, como dito, passaram a influenciar e a reivindicar uma agenda mais participativa na construção de políticas públicas. O Pronaf, de fato, foi uma das primeiras políticas a ser direcionada exclusivamente para os agricultores familiares que, até então, tinham poucas condições de acessar programas de crédito rural. De alguma maneira, portanto, o programa se estabeleceu com o objetivo de incentivar a

${ }^{6}$ Brasil: a gestão da agricultura, do desenvolvimento rural e dos recursos naturais. (Tradução nossa) 
produção desses agricultores com vistas ao mercado, como indicado pelo Banco Mundial, o que gerou e ainda gera uma série de questionamentos ${ }^{7}$. Entretanto, isso não significou a redução do papel estatal na agricultura ou nas políticas públicas; ao contrário, representou um comportamento mais forte da União quanto às políticas de desenvolvimento.

Ainda assim, iniciava-se uma nova tendência de atuação do Estado quanto ao desenvolvimento do rural brasileiro. É preciso dizer, contudo, que mesmo que a década de 1990 tenha sido marcada por uma crise na agricultura ${ }^{8}$, essa nova tendência também não significou, ainda que a longo prazo, uma redução no aporte de recursos e estratégias direcionadas à produção de grande escala. Afirma-se que ambos os projetos são marcados por disputas - entre eles, inclusive - e, mesmo que as políticas para a agricultura familiar tenham alcançado gradual relevância, o modelo de agronegócio continuou sendo prioridade, principalmente com a retomada da balança comercial favorável às exportações na passagem do século.

É por esse viés que Delgado (2010) sugere que, do ponto de vista político, considerando as perspectivas futuras para o meio rural brasileiro, a década de 1990 pode ser interpretada como crucial para dois modelos distintos do rural brasileiro. De um lado, ela contribuiu para reafirmar "a continuidade do padrão dominante de relações economia-meio rural no Brasil" (DELGADO, 2010, p. 50) com o agronegócio e, do outro, possibilitou o avanço para "uma visão alternativa acerca do significado do rural e do desenvolvimento rural e para a democratização das relações sociais e políticas no campo" (DELGADO, 2010, p. 50).

A inserção dessa visão alternativa de desenvolvimento rural, influenciada pelo contexto da redemocratização, da participação dos movimentos sociais e das sugestões de organismos internacionais não está isenta de provocar debates sobre suas possíveis contradições. Porém, é clara a sua distinção quanto ao projeto do agronegócio, "pautado fundamentalmente pela expansão da agricultura de exportação estruturalmente complementar ao 'ajustamento constrangido à globalização"” (DELGADO, 2010, p. 57).

$\mathrm{Na}$ disputa por novas interpretações do desenvolvimento rural, essa perspectiva alternativa ganha destaque com a criação, em 1999, do Ministério do Desenvolvimento Agrário,

\footnotetext{
${ }^{7}$ Para maior compreensão ver Aquino e Schneider (2015); Grisa, Wesz Júnior e Buchweitz (2014); Carneiro (1997).

8 Delgado (2010) aponta para um conjunto de medidas que afetaram negativamente o comportamento da agricultura - incluindo a familiar - ao longo da década de 1990. Dentre outros fatores, três políticas econômicas estiveram à frente desse processo: i) "a liberalização comercial e o desmonte do modelo de intervenção do Estado na agricultura que prevaleceu até a década de 1980" (p. 46); ii) "a adoção do Plano Real em 1994, que levou a uma queda da renda real do setor agrícola de cerca de $20 \%$ a $30 \%$, no primeiro semestre de 1995 ” (p. 46) e iii) "a considerável valorização da taxa de câmbio até 1998" (p. 46).
} 
o MDA. O órgão esteve voltado para atender, preferencialmente, a agricultura familiar. A intenção do Governo, como esclarece Grisa e Schneider (2015), era que ele atuasse com políticas diferenciadas em relação àquelas promovidas pelo Ministério da Agricultura, Pecuária e Abastecimento - MAPA, em que, tradicionalmente, se priorizava o atendimento aos grandes produtores e proprietários de terra.

Em síntese, a redemocratização fortaleceu a reorganização dos movimentos sociais do campo. Desde então, algumas conquistas puderam ser visualizadas como, por exemplo, a abertura de espaços de luta e de participação. Essa conjuntura resultou em certa mudança na postura do Estado e dos movimentos sociais, que estabeleceram canais de diálogo. Esses movimentos, então, chamaram para si o protagonismo na disputa por uma agenda de políticas públicas para o espaço rural brasileiro. Na mesma perspectiva, a influência de novos referenciais setoriais e globais, trazidos tanto pelas vivências dos atores brasileiros quanto dos organismos internacionais, contribuíram para que novas regras e ferramentas de políticas pudessem ser pensadas e executadas, principalmente aquelas direcionadas aos agricultores familiares. Fortalecia-se, então, um caminho de propostas alternativas ao desenvolvimento rural.

\section{APONTAMENTOS FINAIS}

Aparentemente, o debate sobre as políticas de desenvolvimento tem valorizado a participação social, referindo-se à necessidade de que os processos decisórios sejam tomados pelos atores sociais envolvidos. Entretanto, isso não significa dizer que as políticas têm conseguido concretizar tais processos, e mais, que se tenha fortalecido o papel da identidade na construção do desenvolvimento. Os principais motivos estão relacionados ao complexo desenho das políticas e suas articulações institucionais, ou seja, sobretudo, um problema de gestão. (ABDALA, 2017). Tais características criam obstáculos para os atores sociais que estão na ponta, especialmente agricultores familiares. Assim, por meio de olhar mais atento, é possível afirmar que os espaços políticos instituídos carecem de maior vigor (ABDALA, 2017).

Uma observação feita por Dagnino (2002) parece importante, e se refere a um entendimento bastante comum nos debates acerca dos "encontros" entre sociedade civil e Estado na construção de uma política pública, trata-se do entendimento de que o resultado é, sempre, a produção de políticas fragmentadas, setorizadas, compensatórias, paliativas etc. Por um lado, argumenta a autora, é fácil concordar com tais assertivas; por outro, é preciso um 
exame mais minucioso dos pressupostos que parecem condicionar esse cenário. Se o problema fundamental de tal relação está implícito nos modelos de formulação de programas, políticas públicas e suas implicações - o que é frequente -, percebe-se que os obstáculos transcendem “a dimensão da participação da sociedade civil [...] e se remetem ao âmbito mais amplo - e mais complexo - dos modelos de gestão do Estado [...]" (DAGNINO, 2002, p. 298).

Compreende-se que a instituição de espaços participativos tem papel fundamental no jogo político que perpassa a valorização e legitimação de interesses identitários. A negociação das demandas dos atores sociais contribui, inclusive, para a (re)construção e afirmação das identidades, uma vez que são frutos de processos históricos e relacionais, como afirma Cruz (2007). Políticas voltadas para agricultura familiar, mas que contemplam ribeirinhos, quilombolas e indígenas, necessitam não apenas reconhecer a importância das identidades no processo decisório, mas justamente fornecer capacidades institucionais para que as demandas e disputas possam ser revertidas em ações concretas.

Pensar a identidade no processo decisório é aproximar interesses particulares da agenda do desenvolvimento, promovendo não apenas demandas econômicas puras, mas aquelas que decorrem da vivência dos atores envolvidos em seus contextos territoriais. Assim, é dar maiores garantias para que o desenvolvimento possa ocorrer também em suas dimensões sociais, culturais e ambientais, possibilitado a emancipação das liberdades de escolha da população envolvida.

\section{REFERÊNCIAS}

ABDALA, Bruno. Participação social e governança territorial no Programa Territórios da Cidadania: um estudo sobre o colegiado territorial do Vale do Paranã, GO. 2017. Dissertação (Mestrado em Geografia) - Universidade Federal Fluminense, Niterói.

ALMEIDA, Maria Geralda de. "Fronteiras, Territórios e Territorialidades". Revista da ANPEGE, n.2, v.1, p. 103-114, 2005.

AQUINO, Joacir. Rufino. de; SCHNEIDER, Sérgio. "O Pronaf e o desenvolvimento rural brasileiro: avanços, contradições e desafios para o futuro”. In: GRISA, Cátia.; SCHNEIDER, Sérgio. (Org.). Políticas públicas de desenvolvimento rural no Brasil. Porto Alegre: Editora da UFRGS, 2015. p. 53-81.

ARRETCHE, Marta. Democracia, federalismo e centralização no Brasil. Rio de Janeiro, Editora FGV/Editora Fiocruz, 2012. 
BANCO MUNDIAL. Governance and development. Washington, DC: The World Bank, 1992.

BONNAL, Philippe.; MALUF, Renato. S. "Políticas de desenvolvimento territorial e multifuncionalidade da agricultura familiar no Brasil”. Política e sociedade, v. 8, n. 14, p. 211-250, 2009.

BRASIL. Decreto de 25 de fevereiro de 2008. Institui o Programa Territórios da Cidadania e dá outras providências. Presidência da República, Casa Civil, Subchefia para Assuntos Jurídicos, Brasília, 2008.

CARNEIRO, Maria. José. "Política pública e agricultura familiar: uma leitura do Pronaf”. Estudos sociedade e agricultura, n. 8, p. 70-82, 1997.

CASTELLS, Manuel. O poder da identidade. Tradução: Klauss Brandini Gerhardt. São Paulo: Paz e Terra, 1999.

CRUZ, Valter do Carmo. Itinerários teóricos sobre a relação entre território e identidade. In: BEZERRA, Amélia Cristina Alves. et. Al. (Org.) Itinerários Geográficos. Niterói: EdUFF, 2007. p. 13-35.

DAGNINO, Evelina. Sociedade civil, espaços públicos e a construção democrática no Brasil: limites e possibilidades. In: São Paulo: Paz e Terra, 2002. p. 279-301. . (Org.). Sociedade civil e espaço público no Brasil. “Sociedade civil, participação e cidadania: de que estamos falando?” In: MATO, D. (Coord.). Políticas de ciudadanía y sociedad civil en tiempos de globalización. Caracas: FACES, 2004. p. 95-110.

DELGADO, Nelson Giordano. “O papel do rural no desenvolvimento nacional: da modernização conservadora dos anos 1970 ao Governo Lula”. In: (Coord.). Brasil rural em debate: coletânea de artigos, Brasília, CONDRAF/MDA, 2010. p. 28-77.

FAVARETO. Alisson. "As tentativas de adoção da abordagem territorial do desenvolvimento rural - Lições para uma nova geração de políticas públicas". Raízes, v.28/29, n.1/2, p. 58-62, 2009.

FERRÃO, João.O ordenamento do território como política pública. Lisboa: Fundação Calouste Gulbenkian, 2014, capítulos 1, p. 25-45.

"Responsabilidade social territorial e localismo ético". Revista de Economia Solidária, v. 5, p. 18-39, 2012.

FERREIRA, Alvaro. "A imagem virtual transformada em paisagem e o desejo de esconder as tensões do espaço: por que falar em atores, agentes e mobilizações?" In FERREIRA, Alvaro. et al (Org.). Metropolização do espaço: gestão territorial e relações urbano-rurais. Rio de Janeiro: Consequência, 2013. 
FOUILLEUX, Ève. "Analisar a mudança: políticas públicas e debates num sistema em diferentes níveis de governança”. Estudos sociedade e agricultura, v. 19, n. 1, p. 88-125, 2011.

FUINI, Lucas Labigalini. Manifestações da governança territorial no Brasil: uma análise do circuito das águas paulista e do circuito das malhas do sul de minas gerais. Tese (doutorado em Geografia) - Instituto de Geociências e Ciências Exatas, Universidade Estadual Paulista, São Paulo, 2010.

GRISA, Cátia.; SCHNEIDER, Sérgio. "Três gerações de políticas públicas para a agricultura familiar e formas de interação entre sociedade e Estado no Brasil". In: . (Org.). Políticas públicas de desenvolvimento rural no Brasil. Porto Alegre: Editora da UFRGS, 2015. p.19-50.

GRISA, Cátia.; WESZ JUNIOR, Valdemar.; BUCHWEITZ, Vitor Duarte. "Revisitando o Pronaf: velhos questionamentos, novas interpretações". Revista de economia e sociologia rural, v.52, n. 2, p. 323-346, 2014.

HAESBAERT, Rogério. "Dilema de Conceitos: Espaço-Território e contenção territorial". In: SAQUET, Marcos Aurelio.; SPOSITO, Eliseu Savério. (Org.). Território e territorialidades: teorias, processos e conflitos. São Paulo: Expressão Popular, 2009. p. 95120.

HALL, Stuart. A identidade cultural na pós-modernidade. Tradução: Tomaz Tadeu da Silva e Guacira Lopes Lobo. Rio de Janeiro: DP\&A, 1997. p. 07-23.

HESPANHOL, Rosangela Aparecida Medeiros. "A adoção da perspectiva territorial nas políticas de desenvolvimento rural no Brasil”. Campo-Território: revista de geografia agrária, v. 5, n.10, p. 123-147, 2010.

JOBERT, Bruno.; MULLER. Pierre. L'Etat en action. Politiques publiques et corporatismes. Revue française de science politique, Paris, v. 38, n. 3, p. 433-435, 1988.

MONTENEGRO GÓMEZ, Jorge Ramón. Desenvolvimento em (des)construção: narrativas escalares sobre desenvolvimento territorial rural. Tese (doutorado em geografia) - Faculdade de Ciências e Tecnologia, Universidade Estadual Paulista, São Paulo, 2006.

RODRIGUES, Juliana Nunes. "Participação e cooperação nas escalas locais em dois modelos de Estados: França e Brasil”. In: CASTRO, I. E. de; RODRIGUES, J. N.; RIBEIRO, R.W. (Org.). Espaços da democracia: para a agenda da geografia política contemporânea. Rio de Janeiro: Bertrand Brasil, 2013. p. 87-116.

SCHNEIDER, Sérgio. "Situando o desenvolvimento rural no Brasil: o contexto e as questões em debate.” Revista de Economia Política, v. 30, n. 3 (119), p. 511-531, 2010.

SEN, Amartya. Desenvolvimento como liberdade. São Paulo:Companhia das Letras, 2002. 
SOUZA, Edilson Almeida de. "Influência do discurso do Banco Mundial nas políticas públicas de desenvolvimento territorial no Brasil”. Papers do NAEA - Núcleo de Altos Estudos Amazônicos. N.338, p. 1-23, dez. 2014.

TUAN, Yi-Fu. Topofilia: Um estudo da percepção, atitudes e valores do meio ambiente. Tradução: Lívia de Oliveira. São Paulo/Rio de Janeiro: Difel. 1980.

Recebido em Março de 2019

Aprovado em Maio de 2019

Publicado em Agosto de 2019 